\title{
Single Droplet Combustion Characteristics of Petroleum Diesel- Philippine Tung Biodiesel Blends
}

\author{
Nurkholis Hamidi* and Joko Nugroho \\ Department of Mechanical Engineering, Faculty of Engineering, Brawijaya University, Indonesia
}

('Corresponding author's e-mail: hamidy@ub.ac.id)

Received: 27 February 2021, Revised: 28 June 2021, Accepted: 29 July 2021

\begin{abstract}
The purpose of the present study is to investigate the effects of fuel blending of petroleum diesel and biodiesel made from Philippine Tung on the combustion characteristics of fuel droplets. In this study, petroleum diesel was mixed with biodiesel at volume percentages of 0 to $100 \%$ to produce 5 fuel blends. The ratios of fuel blends (petroleum volume/biodiesel volume) were 100:0 (P100), 75:25 (BP25), 50:50 (BP50), 25:75 (BP75) and 0:100 (B100). Single droplet combustion experiments were prepared to understand the combustion characteristics at 3 levels of ambient pressure (100, 200 and $300 \mathrm{kPa})$. Observations were carried out on the ignition delay time, the burning rate constant, droplet temperature, and the flame visualization. The results showed some effects of the adding of biodiesel in petroleum diesel and the chamber pressure on droplet combustion characteristics. The adding of biodiesel into petroleum diesel resulted in a shorter ignition delay time and higher burning rate constants. But, the lower heating value of biodiesel caused the lower flame temperature. The possibility of micro-explosion also increased due to the mixing of fuel. On the other hand, increasing the chamber pressure also resulted in shorter ignition delay, higher burning rate, and higher combustion temperature. The higher ambient pressure also compressed the flame dimension and enhanced the onset of micro-explosion.
\end{abstract}

Keywords: Biodiesel, Philippine Tung, Reutealis trisperma (Blanco) Airy Shaw, Droplet combustion, Flame

\section{Introduction}

The rapid growth of industrialization and the human population resulted in high demand for energy consumption. The long-term use of fossil fuels faces problems due to the depletion of energy reserves and their devastating impact on the environment and human health due to the burning process of fossil fuels $[1,2]$. Several studies have also reported that the use of fossil fuels contributes greatly to the emission of greenhouse gases that cause global warming effects [2,3]. Therefore, it is important to explore environmentally friendly renewable fuels to replace fossil fuels [4].

Diesel engines require large amounts of diesel fuel since they are widely used in the transportation and industrial sectors. Biodiesel has been proposed as alternatives to substitute petroleum diesel fuels for internal combustion engines because of some advantages [1,2]. Biodiesel is a renewable, less lifecycle greenhouse gas, clean-burning fuel. Biodiesel can be produced from bio-oil from plant seeds through the chemical reactions processes of transesterification, esterification, methanolysis, etc. The properties of biodiesel are generally close to petroleum diesel $[5,6]$, so it can be used usually as a mixed fuel in existing diesel engines without or with minor modification [6,7]. Maneechakr and Karnjanakom, [5] reported that FAME production via methanolysis of waste cooking palm oil has properties of density, viscosity, flash point, acid value, and iodine value which could be applied for diesel engines, complying with ASTM specifications [5]. High-quality biodiesel (H-FAME) from jatropha oil also can be produced via the transesterification process [6]. It was reported that all properties of H-FAME satisfied the requirements of all biodiesel standards, including EU and US standards. It also can be applied in a diesel engine with a $10 \%$ blended ratio.

Transesterification has been widely used to reduce the viscosity of bio-oil and for the conversion of triglycerides into fatty acid esters. The physical characteristics of esters by the transesterification process are generally very close to those of petroleum diesel fuels. However, the final properties of biodiesel depend on the raw material. The bio-oil consists of a complex mixture of alkyl ester fatty acid compounds 
(FAAE) with various carbon chains and saturation degrees. The complex mixtures influenced the characteristic of biodiesel [8,9]. Biodiesel contains a lot of unsaturated fatty acids is usually more reactive during the combustion process. The unsaturated fatty acids with or more double bonds $(\mathrm{C}=\mathrm{C})$ generally have lower viscosity, heating value, boiling point, melting point, and cetane number comparing with saturated fatty acids [10-12].

There are some reports related to engine performance using biodiesel $[8,9,13]$. It is reported that there are some advantages of biodiesel for engine performance. The oxygen levels in biodiesel improve the combustion process in the cylinder to complete combustion. It results in less carbon monoxide, unburned hydrocarbon, and particulate matter emissions. Although biodiesel has many advantages, there are some properties of biodiesel cause problems when it is applied as fuel in diesel engines. Several problems arise due to the nature of biodiesel. It usually has a higher viscosity, density, and cetane number, but a lower calorific value than petroleum diesel [14]. The lower calorific value often weakens the performance of a direct injection diesel engine. Some researchers suggest mixing biodiesel with petroleum diesel to make up for these weaknesses [14,15]. Although the addition of biodiesel to petroleum diesel will result in a loss of engine power and an increase in fuel consumption primarily due to a lower calorific value of biodiesel, biodiesel with a small mixed volume-based content can replace petroleum diesel without significantly sacrificing engine power.

Many studies have been investigated the direct use of biodiesel and diesel mixtures in compressed ignition engines [14-16]. They reported that adding biodiesel in petroleum diesel reduces CO and HC emissions from the engine significantly. It is a good indication for solving environmental problems. However, some results show that the use of biodiesel fuel still causes more NOx emissions. The studies also evaluated the engine performance. They reported that applied biodiesel in diesel engines influences engine performance (power, torque and ignition delay). Although the improvements in emission characteristics and engine performance can be understood by direct observation of the engine performance, a more comprehensive analysis through combustion studies is essential for understanding the combustion process and fuel energy generation. Recent studies have adopted a droplet combustion approach to explore in detail the combustion behavior occurring in diesel engines $[17,18]$. Understanding the phenomenon of combustion is necessary for the improvement of the internal combustion engine system.

Recently, Indonesia cultivates Philippine Tung or Reutealis trisperma (Blanco) Airy Shaw as a source of bio-oil. This plant is not a food plant, and its seeds have a high content of oil. The immersion of Philippine Tung seed could reach $50 \%$ of its mass, so it becomes a potential source of biofuel. The oil also has a high content of fatty acids, which is more than $88 \%$. More than $80 \%$ of the fatty acids of Philippine Tung oil are unsaturated fatty acids (oleic acid, linoleic acid and $\alpha$-eleostearic acid), and less than $20 \%$ are saturated fatty acids (palmitate acid and stearic acid). This oil is prospective to be processed as Fatty Acid Methyl Ester (FAME) or biodiesel with good fuel characteristics [19,20]. The high content of unsaturated fatty acids in Philippine Tung oil makes it potential to make more reactive biodiesel products. Unsaturated fatty acids can usually be more reactive due to the presence of double and triple-bonded carbon atoms because these are weaker pi bonds than single bond saturated hydrocarbons, so they can be broken down easily compared to saturated fatty acids during the reaction due to the presence of weaker pi bonds. Therefore, the present study aimed to investigate the combustion characteristics (ignition delay time, the burning rate constant, droplet temperature and the flame visualization) of petroleum diesel-biodiesel blends of a single fuel droplet.

\section{Materials and methods}

\section{Material}

This study used petroleum diesel and biodiesel for the experimental materials. The petroleum diesel is commercially provided by Pertamina Indonesia, Ltd, while the biodiesel produced by esterification of bio-oil from Philippine Tung seed. The crude oil was made from Philippine Tung seed using a pressurized filter machine. The crude oil is then subjected to a degumming process with the addition of $1 \%(\mathrm{v} / \mathrm{v})$ $\mathrm{H}_{3} \mathrm{PO}_{4}$ while stirring for $60 \mathrm{~min}$ at a temperature of $50-60{ }^{\circ} \mathrm{C}$. It is deposited for at least $3 \mathrm{~h}$, then the oil is separated from the gum. After the degumming process, the bio-oil was then carried out by an esterification process. Bio-oil, ethanol, and catalyst of sulfuric acid $\left(\mathrm{H}_{2} \mathrm{SO}_{4}\right)$ were selected as the material to produce the biodiesel. The observation was carried out on the droplet of petroleum diesel, biodiesel, and blended fuel of petroleum and biodiesel. The ratios of blended fuels (petroleum volume/biodiesel volume) were 100:0 (P100), 75:25 (BP25), 50:50 (BP50), 25:75 (BP75) and 0:100 (B100). 


\section{Experimental setup and method}

We used the same research installation as our previous study [18]. Figure 1 shows the experimental installation. A pressurized chamber was used to observe the combustion of single fuel droplets. In this study we performed the combustion process in atmospheric air temperature (about $30^{\circ} \mathrm{C}$ ) and 3 levels of chamber pressure. i.e. 100,200 and $300 \mathrm{kPa}$. This test method used a single fuel compound with a suspended droplet.

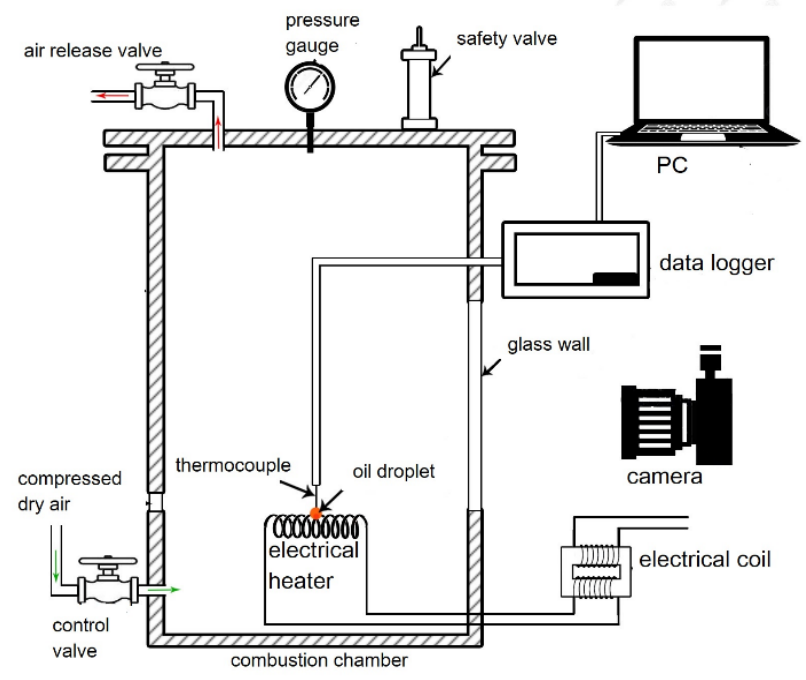

Figure 1 The schematic diagram of experimental setup and apparatus.

The droplet was formed using a microsyringe with a diameter of about $1.5 \mathrm{~mm}$ and deposited on the tip of the thermocouple. We used a K-type thermocouple to measure the droplet temperature during the combustion occurred.

An electrical coil heater is charged with a $12 \mathrm{~V} 5 \mathrm{~A}$ accumulator to ignite the fuel droplet. To avoid the influence of heat from the heater, the accumulator is immediately turned off after the droplet is successfully ignited. During the heating and ignition process, the temperature in the middle of the oil droplet is recorded by the thermocouple and obtained by a personal computer connected to the data logger. The whole process of droplet combustion, from the initial ignition until it burned out, was recorded by a digital camera. The video shooting process took place at a frame rate of 60 fps to allow the determination of ignition and burnout times. Then, using an image analysis some of the combustion characteristics (ignition delay time, constant of burning rate and the flame dimension) are determined.

\section{Results and discussion}

\section{Ignition delay time and burning rate constant of the droplets combustion}

In this study, ignition delay time of the droplet combustion is defined as the time interval from the moment the droplet is heated by the heater until the initial flame occurs. The observation results of the time delay for ignition of combustion droplets are shown in Figure 2. It can be seen that the ignition delay time of petroleum diesel (P100) is longer than the biodiesel (B100). Under $100 \mathrm{kPa}$ chamber pressure, the B100 droplet fired after about $2.7 \mathrm{~s}$, while the P100 droplet fired $3.9 \mathrm{~s}$ after turning on the heater. For the blended fuels, adding biodiesel to diesel oil (BP25, BP50 and BP75) also reduced the ignition delay. The ignition delay is reduced in proportion to the increase in biodiesel in the blended fuel.

Normally, biodiesel has a higher density and boiling point compared to petroleum diesel. The higher boiling points of biodiesel often resulted in a longer ignition delay time [19,20]. However, heating biodiesel at high temperatures will break down the high-molecular into the low-molecular weight esters. The ignition delay time reduces since the low-molecular-weight esters can be gasified rapidly to produce volatile combustion compounds thus ignited earlier [19-21]. In addition, the rich oxygen content of biodiesel is also the reason for the short ignition delay time of biodiesel [23,24]. In the ignition delay time, the fuel droplet is heated, evaporated, mixed with oxygen and chemically reacts after reach the 
ignition temperature. The presence of oxygen about $11 \mathrm{wt} \%$ in biodiesel assists the mixing between the fuel and oxygen to fulfill the combustion requirements, so the biodiesel droplet will ignite faster than petroleum diesel. In the case of petroleum diesel, almost no oxygen is present inside the fuel to accelerate the initiation of the combustion process.

The burning rate constant of the droplet combustion was illustrated in Figure 3. The burning rate constant is the slope of the evolution of the squared diameter during the combustion time [25]. A higher value of this constant indicates the combustion occurs faster. It is calculated by using $\mathrm{D}^{2}$ law in the following equation;

$\mathrm{D}(\mathrm{t})^{2}=\mathrm{D}_{\mathrm{o}}{ }^{2}-\beta_{0 .} \mathrm{t}$

$\beta_{0}=\left(D_{o}^{2}-D(t)^{2}\right) / t$

where $\mathrm{D}_{\mathrm{o}}$ : Initial diameter of droplet $(\mathrm{mm})$

$\mathrm{D}(\mathrm{t})$ : Droplet diameter at $\mathrm{t}(\mathrm{mm})$

$\beta_{0}$ : Burning rate constant $\left(\mathrm{mm}^{2} / \mathrm{s}\right)$

$\mathrm{t}$ : Burning rate lifetime (s).

The results indicated the burning rate constant of biodiesel (B100) is higher than petroleum diesel (P100). The addition of biodiesel to the petroleum diesel (B25, B50 and B75) also results in an increase in the burning rate constant of the blended fuels. This result agreed with the ignition delay times. The high combustion rate constants of biodiesel and blended fuels are related to the presence of oxygen in biodiesel [26]. The presence of oxygen in biodiesel causes the oxidation reaction of combustion to occur more easily. On the other hand, Philippine Tung biodiesel is also rich in unsaturated fatty acids (more than 80 $\%)$. The rich content of unsaturated fatty acid in biodiesel led the reaction faster since it is more reactive than a saturated fatty acid. Burning rate is one of the important properties of droplet combustion which shows the combustion acceleration and the combustion power generation. The greater the burning rate, the faster the combustion occurred and the greater the power generated.

Furthermore, the influence of air pressure of combustion chamber on the droplet ignition delay time was shown in Figure 2, while its effect on burning rate constant can be seen in Figure 3. The results show that the increase of chamber pressure from 100 to $500 \mathrm{kPa}$ results in reducing ignition delay time and increasing the burning rate constant of almost all samples. The enthalpy of evaporation usually reduces at a higher chamber pressure. At higher pressure, therefore, the fuel droplet needs less heat input to evaporate and burned faster. When the combustion is carried out under higher pressure, the boiling temperature of fuels increases and the heat-up period becomes longer. However, it decreases the latent heat of evaporation, which would increase the vaporization rate and reaction rate [27]. It may also be that the increase in air pressure causes the fuel and oxygen molecules to become closer together, and the likelihood of a collision between these molecules is higher. It accelerates the combustion reaction to complete faster [8].

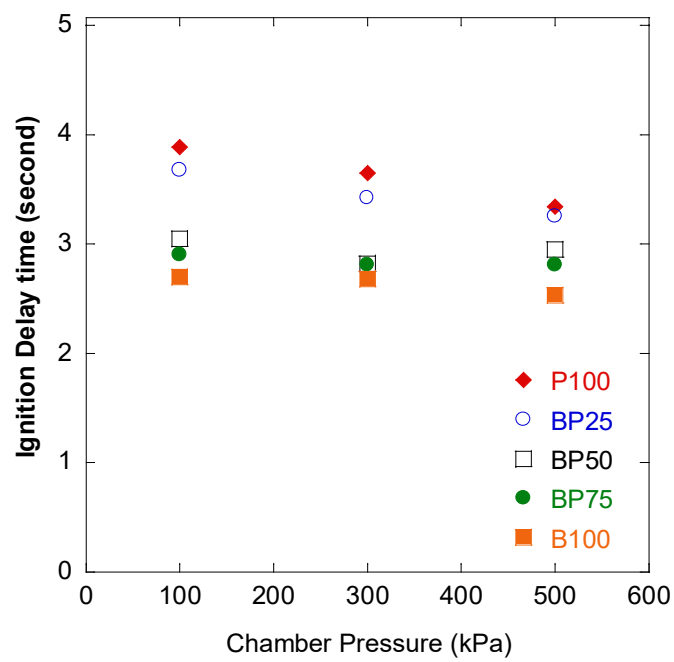

Figure 2 Ignition delay time of droplet. 


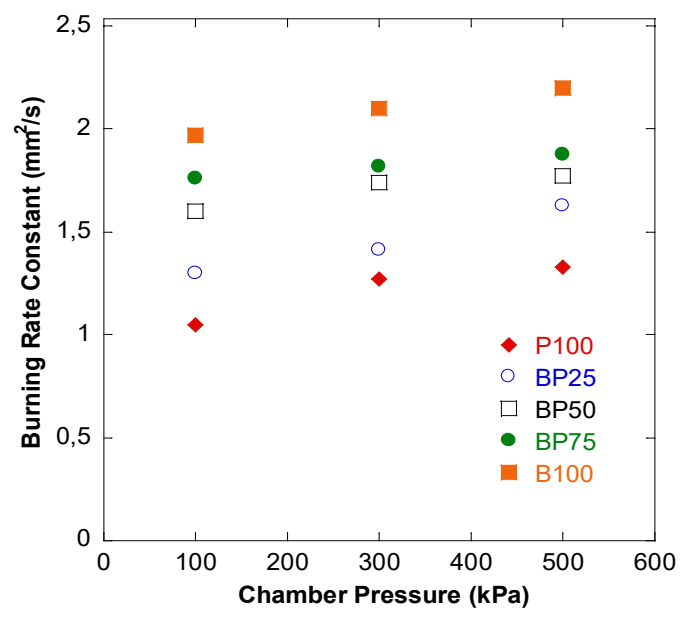

Figure 3 Burning rate constant of droplet.

\section{Maximum temperature of droplet}

Figure 4 shows maximum temperature during the droplet combustion. The maximum droplet temperature occurs almost at the end of the droplet combustion, in which the thermocouple junction is entirely in contact with the flames. The measurement results show that petroleum diesel (P100) has a higher maximum combustion temperature than biodiesel (B100). The maximum temperature of the droplet of petroleum during the combustion carried out at a chamber pressure of $100 \mathrm{kPa}$ was about $492.03{ }^{\circ} \mathrm{C}$, while the combustion of biodiesel was about $435.8^{\circ} \mathrm{C}$. When biodiesel adding to petroleum diesel, it results in a proportional reduction of combustion temperature. Figure 4 also shows the effect of chamber pressure on the resulting combustion temperature. Increasing the chamber pressure in the combustion chamber results in an increase in combustion temperature. Figure 4 also show the effect of chamber pressure on the resulting combustion temperature. Increasing the air pressure in the combustion chamber results in an increase in combustion temperature.

Generally, the droplet temperature is affected by the fuel heating value, burning rate, and heat loss $[28,29]$. The temperature of combustion is an indicator of the amount of energy released during combustion [17]. In this study, the maximum droplet temperature occurs almost at the end of the droplet combustion when the thermocouple junction is almost in contact with the flames. The measurement results show that petroleum diesel has a higher maximum combustion temperature than biodiesel. This behavior may be related to the fuel heating value. The Philippine Tung biodiesel has a caloric value of $39.78 \mathrm{MJ} / \mathrm{kg}$ while petroleum diesel has about $43 \mathrm{MJ} / \mathrm{kg}$ [17]. The higher caloric value of petroleum diesel released more heat energy compared to biodiesel during the combustion. So, the combustion temperature of petroleum diesel is higher than the biodiesel.

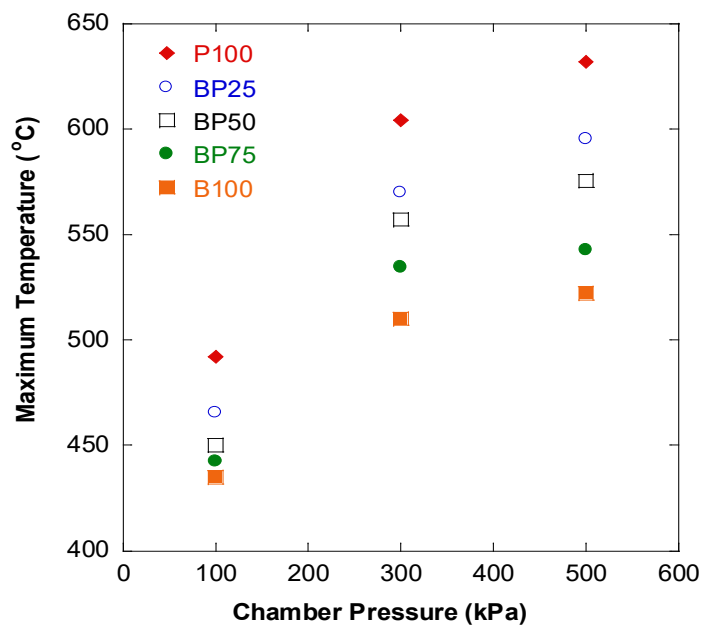

Figure 4 Maximum temperature of droplet. 


\section{Flame dimension}

The flame visualization of biodiesel (B100) droplet burning in 3 levels of air pressure can be seen in Figure 5. It shows a flame visualization from the beginning of the visible flame can be observed until the flame is extinguished. It can be observed that combustion at a chamber with a low ambient pressure takes a longer time. The flame dimension slowly increases at the beginning for the combustion under the pressure of $100 \mathrm{kPa}$, but it is faster for the combustion under 300 and $500 \mathrm{kPa}$.
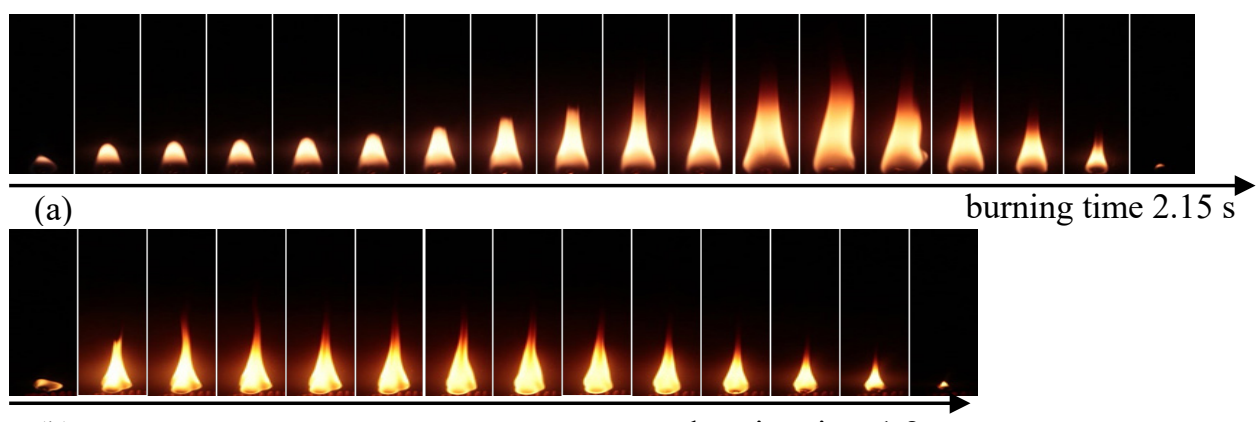

(b)

burning time $1.8 \mathrm{~s}$

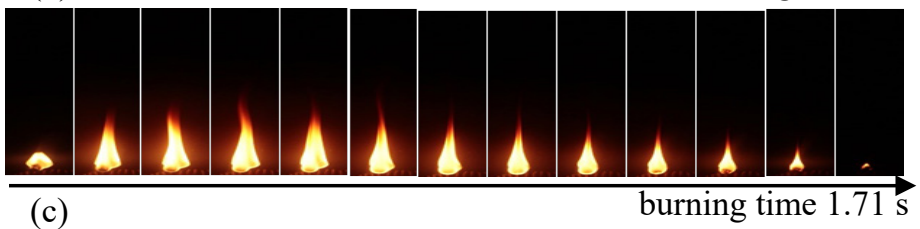

Figure 5 Flame visualization of B100 (a) in $100 \mathrm{kPa}$ chamber pressure, (b) in $300 \mathrm{kPa}$ chamber pressure, and (c) in $500 \mathrm{kPa}$ chamber pressure.

Moreover, flame generated at low ambient pressure also has a relatively larger dimension than a fire at high ambient pressure. The flame at 300 and $500 \mathrm{kPa}$ appears to be shorter and thinner than the fire at $100 \mathrm{kPa}$. Darabkhani et al. [30], explained that the increase of soot in higher pressure led significant change in flame. Under a higher air pressure, the soot particles are difficult to diffuse away from the primary flame region since they have high density than other combustion products. Therefore, the thinner flame occurs due to the oxygen diffusion to the primarily flame region [15]. The specific flame dimensions for the height and width of the flame are plotted in Figures 6 and 7. The results also indicated that petroleum diesel-generated a higher but thinner flame compared to the flame from biodiesel. The dimensions of the flame change to be shorter and thicker when biodiesel is added to petroleum diesel. Petroleum diesel has a lower density and evaporation point than biodiesel. The ease with which petroleum diesel evaporates and the effect of buoyancy force at high temperatures create the flame of petroleum diesel higher than flame of biodiesel.

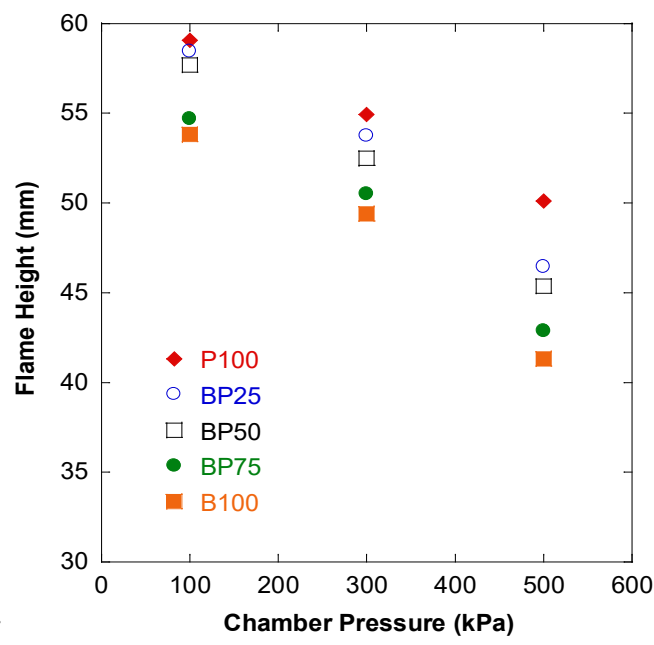

Figure 6 The flame height. 


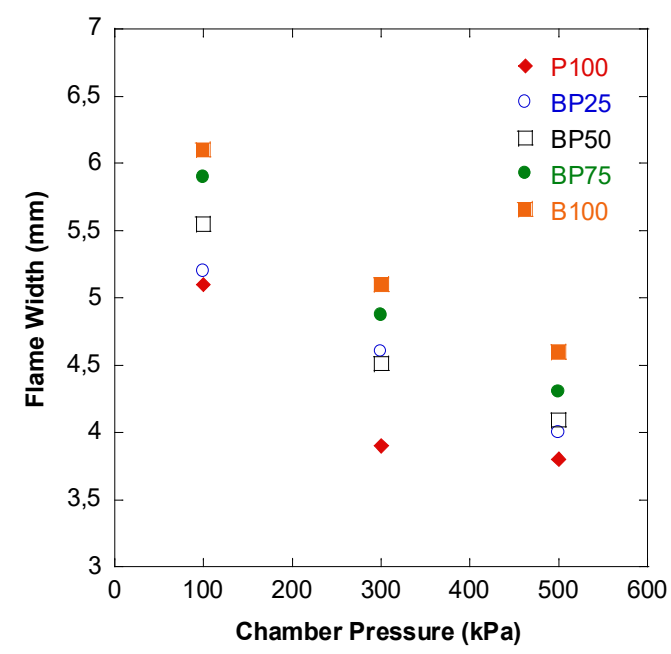

Figure 7 The flame width.

\section{Micro explosion}

In this observation, phenomena of micro-explosion also can be observed from flame visualization. Micro-explosion usually occurs in the combustion of fuel droplets which have many components with different boiling points. A micro-explosion occurs as a result of the evaporation of 2 or more volatile liquid components in a high-temperature environment. During droplet heating, even though the droplet surface has not yet passed the boiling state, the temperature in some areas within the droplet may be higher than the local boiling point due to the presence of lighter components in the droplet. When the temperature inside the droplet is high enough to initiate vapor nucleation, bubbles of vapor will be generated within the droplet. The rapid growth of vapor bubbles then results in a micro-explosion of the droplets $[23,24]$.

In the present study, micro-explosion is characterized by an unstable flame due to bubbles coming out of the main droplet and burning in a short time shown in Figure 8. The micro-explosions can be recognized during the combustion of pure biodiesel (B100) and blended fuels (B25, B50 and B75). The number of micro-explosions is low during the droplet combustion of B100 under ambient pressure of 100 $\mathrm{kPa}$. We only identified that there were 6 micro-explosions. The micro explosion in B100 could be due to the multi-components of fatty acids with different boiling points in Philippine Tung oil as shown in Table 1. There is $19 \%$ of linoleic acid with a lower boiling point of $230{ }^{\circ} \mathrm{C}$ within other fatty acids (oleic, palmitic and stearic) with the boiling points of about $351-390{ }^{\circ} \mathrm{C}$. The intensity of the micro-explosion increased on the combustion of the mixtures of biodiesel and petroleum diesel fuel. The observations showed that there were 31 explosions for B25 and 49 times for B50. Increasing the intensity of microexplosion during the combustion of fuel mixture could be due to the significant difference in boiling point between petroleum diesel and biodiesel [23]. The experimental results also show an increasing probability of a micro-explosion at higher ambient pressures. We identified that micro-explosions occur more frequently at a higher ambient pressure. During the combustion of B100, the occurrence of microexplosion increased from 6 times (in $100 \mathrm{kPa}$ ) to 22 times (in $500 \mathrm{kPa}$ ambient pressure). Also, for the $\mathrm{B} 50$, we found that micro explosion increase from 49 (in $100 \mathrm{kPa}$ ) to 124 times (in $500 \mathrm{kPa}$ ). Cai Sen et al. [23] states that micro explosion is more possible to occur in a higher pressure due to the superheat degree decrease with increasing ambient pressure. 


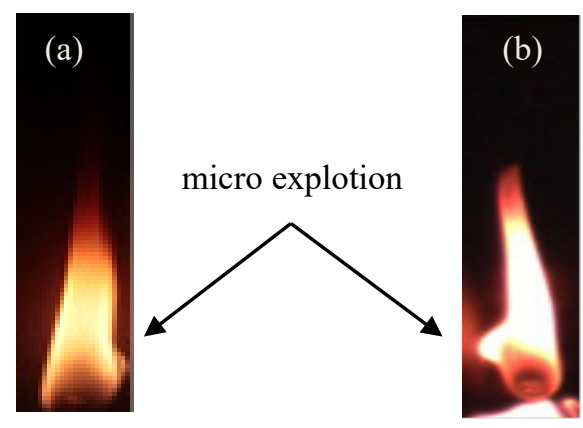

Figure 8 Micro-explosion in droplet combustion (a) B100 and (b) BP50.

Tabel 1 Fatty acids in Philippine Tung oil.

\begin{tabular}{cccc}
\hline No & Fatty Acid & Boiling Point $\left({ }^{\circ} \mathbf{C}\right)$ & $\mathbf{\%}$ \\
\hline 1 & Linoleic & 230 & 19 \\
2 & Oleic & 360 & 12 \\
3 & $\alpha$-eleostearic acid & 390 & 50 \\
4 & Palmitic & 351 & 10 \\
5 & Stearic & 361 & 9 \\
\hline
\end{tabular}

\section{Conclusions}

An experimental study was carried out on burning droplets of petroleum diesel, Philippine Tung bio-diesel and their blends to study the characteristics of droplet combustion. The influences of adding biodiesel in petroleum diesel and the ambient pressure on burning rate constant, ignition delay time, the flame dimension and micro explosion phenomena were observed. The results indicated that the biodiesel of Philippine Tung oil was relatively more reactive than petroleum diesel. Biodiesel has a shorter ignition delay time and a higher burning rate constant compares to petroleum diesel. Furthermore, the adding of biodiesel into petroleum diesel also resulted in a shorter ignition delay period and higher burning rate constants. But, the low heating value of biodiesel results in a decrease in droplet temperature during the combustion process. On the other hand, increasing the ambient pressure also resulted in lower ignition delay, higher burning rate, and higher combustion temperature. The diffusion flame becomes narrower and shorter when the combustion is carried out at higher ambient pressure. In the present study, phenomena of micro-explosion also were observed on burning droplets. It can be recognized that microexplosion occurred in the burning droplet of pure biodiesel and blends fuels. The results show that mixing petroleum diesel with biodiesel increases the possibility of micro-explosion due to the different boiling points of the components of the fuels. The observation results of micro-explosion under a higher ambient pressure show that increasing ambient pressure enhances the onset of micro-explosion.

\section{Acknowledgements}

The author would like to thank Ministry of Education and Culture of the Republic of Indonesia for the grand provided for this research.

\section{References}

[1] SA Khan, Rashmi, MZ Hussain, S Prasad and UC Banerjee. Prospects of biodiesel production from microalgae in India. Renew. Sustain. Energ. Rev. 2009; 13, 2361-72.

[2] M Tabatabaei, M Toehidfar, GS Jouzani, M Safarnejad and M Pazouki. Biodiesel production from genetically engineered microalgae: Future of bioenergy in Iran. Renew. Sustain. Energ. Rev. 2011; 15, 1918-27. 
[3] A Banerjee, R Sharma, Y Chisti and UC Banerjee. Botryococcus braunii: A renewable source of hydrocarbons and other chemicals. Crit. Rev. Biotechnol. 2009; 22, 245-79.

[4] DDLT Ugarte, ME Walsh, H Shapouri and SP Slinsky. The economic impacts of bioenergy crop production on US agriculture. Oak Ridge Natl. Lab. 2000; 292, 5519.

[5] P Maneechakr and S Karnjanakom. A combination of 2k factorial with Box-Behnken designs for FAME production via methanolysis of waste cooking palm oil over low-cost catalyst. J. Environ. Chem. Eng. 2019; 7, 103389.

[6] T Manida, S Amornpoth, K Mongkon, A Jirasak, C Nuwong. High quality jatropha biodiesel (HFAME) and its application in a common rail diesel engine. Renew. Energ. 2017; 113, 660-8.

[7] H Kuszewski. Experimental investigation of the autoignition properties of ethanol-biodiesel fuel blends. Fuel 2019; 235, 1301-8.

[8] SL Ferreira, AM Santos, GR Souza and WL Polito. Analysis of the emissions of volatile organic compounds from the compression ignition engine fueled by diesel-biodiesel blend and diesel oil using gas chromatography. Energy 2008; 33, 1801-6.

[9] SK Aggarwal. Single droplet ignition: Theoretical analyses and experimental findings. Progr. Energ. Combust. Sci. 2014; 45, 79-107.

[10] AJ Folayan, PAL Anawe, AE Aladejare and AO Ayeni. Experimental investigation of the effect of fatty acids configuration, chain length, branching and degree of unsaturation on biodiesel fuel properties obtained from lauric oils, high-oleic and high-linoleic vegetable oil biomass. Energ. Rep. 2019; 5, 793-806.

[11] P Benjumea and JR Agudelo. Effect of the degree of unsaturation of biodiesel fuels on engine performance, combustion characteristics, and emissions. Energ. Fuel. 2010; 25, 77-85.

[12] S Deshmukh, R Kumar and K Bala. Microalgae biodiesel: A review on oil extraction, fatty acid composition, properties and effect on engine performance and emissions. Fuel. Process. Tech. 2019; 191, 232-47.

[13] M Lapuerta, O Armas and JR Fernandez. Effect of biodiesel fuels on diesel engine emissions. Prog. Energ. Combust. Sci. 2008; 34, 198-223.

[14] SK Hoekman, A Broch, C Robbins, E Ceniceros and M Natarajan. Review of biodiesel composition, properties, and specifications. Renew. Sustain. Energ. Rev. 2012; 16,143-69.

[15] KA Abed, MS Gad, AKE Morsi, MM Sayed, SA Elyazees. Effect of biodiesel fuels on diesel engine emissions. Egypt J. Pet. 2019; 28, 183-8.

[16] EK Mohammed and AN Medhat. Experimental investigations of ignition delay period and performance of a diesel engine operated with Jatropha oil biodiesel. Alexandria Eng. J. 2013; 52, 141-9.

[17] Zhu Mingming, M Yu and Zha Dongke. Effect of a homogeneous combustion catalyst on combustion characteristics of single droplets of diesel and biodiesel. Proc. Combust. Inst. 2013; 34, 1537-44.

[18] H Nurkholis, Purnami, W Widya and F Rizal. Pressure effect in droplet combustion of blended fuel on ethanol and Kemiri Sunan (Reutealis Trisperma (Blanco) airy shaw) biodiesel. IOP Conf. Ser. Mater. Sci. Eng. 2019; 494, 012052.

[19] Minister of Energy and Mineral Resources Indonesia. Kemiri Sunan, Available (in Indonesia) at: https://www.esdm.go.id/en/media-center/news-archives/kemiri-sunan-alternatif-pengganti-bbm, accessed October 2020.

[20] A Asif and P Dibyo. The characteristic of the Philippine Tung [Reutealis Trisperma (Blanco) airy shaw] biodiesel processed through two step transesterification process. Jurnal Tanaman Industri dan Penyegar 2012; 3, 193-200.

[22] VD Sonara1 and PR Pravin. A review study on bio-diesel droplet ignition. Int. J. Eng. Res. Tech. $2013 ; 2,2158-70$.

[23] C Shen, WL Cheng and CF Lee. Micro-explosion modeling of biofuel-diesel blended droplets. $S A E$ Int. J. Engines 2011; 4, 1445-53.

[24] A Mohan, CG Lionel, X Jun and M Athanasios. Puffing and micro-explosion of diesel-biodieselethanol blends. Fuel 2016; 166, 59-66. 